\title{
Expression of excision repair cross complementing group 1 and prognosis in adrenocortical carcinoma patients treated with platinum-based chemotherapy
}

\author{
Cristina L Ronchi ${ }^{1,2}$, Silviu Sbiera ${ }^{1}$, Luitgard Kraus ${ }^{1}$, Sebastian Wortmann ${ }^{1}$, \\ Sarah Johanssen ${ }^{1}$, Patrick Adam ${ }^{3}$, Holger S Willenberg ${ }^{4}$, Stefanie Hahner ${ }^{1}$, \\ Bruno Allolio ${ }^{1}$ and Martin Fassnacht ${ }^{1}$
}

\footnotetext{
${ }^{1}$ Endocrine and Diabetes Unit, Department of Medicine I, University Hospital, University of Würzburg, Josef-Schneider-Strasse 2, 97080 Würzburg, Germany

${ }^{2}$ Endocrine Unit, Fondazione IRCCS Ospedale Maggiore Policlinico and Department of Medical Sciences, University of Milan, Milan, Italy

${ }^{3}$ Institute of Pathology, University of Würzburg, Würzburg, Germany

${ }^{4}$ Department of Endocrinology, Diabetes and Rheumatology, University Hospital Düsseldorf, Düsseldorf, Germany

(Correspondence should be addressed to M Fassnacht; Email: fassnacht_m@medizin.uni-wuerzburg.de)
}

\begin{abstract}
Therapeutic progress in adrenocortical carcinoma (ACC) is severely hampered by its low incidence. Platinum-based chemotherapies are the most effective cytotoxic treatment regimens in ACC but response rates remain $<50 \%$. In other tumor entities, expression of excision repair cross complementing group 1 (ERCC1) predicts resistance to platinum compounds. Therefore, we correlated ERCC1 protein expression and clinical outcome. We have retrolectively established adrenal tissue microarrays and analyzed prospectively samples from 163 ACCs, 15 benign adrenal adenomas, and 8 normal adrenal glands by immunohistochemistry for ERCC1 protein expression. Detailed clinical data were available by the German ACC Registry. ERCC1 protein was highly expressed in all normal adrenal glands, 14 benign tumors (93\%) and in 75 ACCs (47\%). In ACC, no differences in baseline parameters were found between patients with and without ERCC1 expression. Detection of ERCC1 was not correlated with survival in patients who never received platinum-based chemotherapy. In platinum-treated patients $(n=45)$, objective response to platinum compounds was observed in $3 / 21$ patients (14.3\%) with high ERCC1 expression and in $7 / 24$ patients $(29.2 \%)$ with low ERCC1 expression $(P=0.23)$. ERCC1 expression was strongly correlated with overall survival after platinum treatment (median: eight months in patients with high ERCC1 versus 24 months in low ERCC1 expression, hazard ratio (HR) 2.95 (95\% confidence interval (Cl) 1.4-6.2), $P=0.004)$. Multivariate analysis confirmed that high ERCC1 expression was a predictive factor for poor prognosis in platinum treated patients $(\mathrm{HR} 2.2,95 \% \mathrm{Cl} 1.0-4.5$, $P=0.038$ ). Our findings suggest that ERCC1 expression is the first factor for predicting survival in ACC patients treated with platinum-based chemotherapy.
\end{abstract}

Endocrine-Related Cancer (2009) 16 907-918

\section{Introduction}

Adrenocortical carcinoma (ACC) is a rare tumor with an annual incidence $<2 / 1$ million and an incompletely understood pathogenesis (Wajchenberg et al. 2000, Allolio \& Fassnacht 2006, Koschker et al. 2006, Libè et al. 2007). This low incidence has hampered significant therapeutic progress in the past and up to now there has been no single randomized trial published. Despite best care, the overall survival (OS) rate at 5 years is $25-50 \%$ in most series (Allolio \& Fassnacht 2006, Koschker et al. 2006, Assiè et al. 2007, Libè et al. 2007, Fassnacht et al. 2008). Surgery is the treatment of choice in early to intermediate stages aiming at complete tumor removal (Schteingart et al. 
2005, Abiven et al. 2006, Allolio \& Fassnacht 2006), but most patients experience a disease relapse (Stojadinovic et al. 2002, Allolio \& Fassnacht 2006). Mitotane is the only approved drug in ACC treatment but the average response rate is only about $25 \%$ (Hahner \& Fassnacht 2005, Terzolo et al. 2007). Several cytotoxic drugs have been investigated in small case series (Ahlman et al. 2001, Allolio et al. 2004, Quinkler et al. 2008) and cisplatin has been the most widely used and most effective drug, either alone or in combination with other agents (Ahlman et al. 2001, Schteingart et al. 2005). The most encouraging results till date were observed by Berruti et al. (2005) using the combination regimen of mitotane with etoposide, doxorubicin and cisplatin (EDP) in the largest published trial including 72 patients with an objective response rate of $49 \%$. However, this regimen has significant toxicity. Therefore, the determination of parameters that identify patients who will benefit from this cytotoxic therapy would have strong clinical implications and allow physicians to optimize patient care. However, up to date, data on prognostic factors in ACC are limited and no predictors of treatment response have been established (Schteingart et al. 2005).

Platinum compounds exert their cytotoxic effects by binding to DNA and forming DNA adducts leading to interstrand or intrastrand cross links that disrupt the structure of the DNA molecule. These changes eventually trigger apoptosis and cell death. However, DNA repair mechanisms, in particular nucleotide excision repair (NER) and mismatch repair, can counteract these effects and, therefore, play a key role in mediating platinum resistance in cancer patients (Reed 1998). The excision repair cross complementing group 1 (ERCC1) protein performs an essential late step in the NER pathway and plays a critical role in removing drug-induced DNA adducts (Tsodikov et al. 2007). Previous in vitro studies have linked ERCC1 expression to platinum resistance in different cancer cell lines (Chang et al. 2005, Cummings et al. 2006). Moreover, several retrospective clinical studies in different cancer types demonstrated a negative correlation between ERCC1 mRNA (Shirota et al. 2001, Fautrel et al. 2005, Joshi et al. 2005, Ceppi et al. 2006, Bellmunt et al. 2007) or protein expression (Olaussen et al. 2006, Handra-Luca et al. 2007, Kwon et al. 2007, Steffensen et al. 2008) and response to platinum-containing drugs (cisplatin, carboplatin, oxaliplatin). Recently, also prospective clinical trials have confirmed that assessment of ERCC1 expression may predict the subsequent response to cisplatin in patients affected by non-small cell lung cancer (Cobo et al. 2007, Darcy et al. 2007).
Our study was performed to investigate if ERCC1 expression might predict clinical outcome also in patients with ACC. We, therefore, studied ERCC1 protein expression by immunohistochemistry in a large number of ACCs and correlated the expression with baseline histopathological and clinical characteristics. In addition, we assessed the relationship between ERCC1 expression and objective response to platinumbased chemotherapy and survival.

\section{Materials and methods}

\section{Patients and tissues}

A total of 190 adrenocortical tumor tissues were collected retrolectively from patients undergoing adrenalectomy due to ACC $(n=175)$ or benign lesions $(n=15)$, such as aldosterone-producing $(n=5)$, cortisolproducing $(n=5)$ or hormonally inactive adenomas $(n=5)$ in 72 German hospitals between 1989 and 2007 (see Supplementary Fig. 1, which can be viewed online at http://erc.endocrinology-journals.org/supplemental/). Eight normal human adrenal glands derived from tumor nephrectomies were also included. A total of 143 ACC samples were derived from primary tumors, 18 from local recurrence and 17 from distant metastases. The diagnosis of ACC was based on established clinical, biochemical, and morphological criteria (Allolio \& Fassnacht 2006), and all histological diagnoses were confirmed (including Weiss, Hough, and van Slooten score and Ki67 index) by the reference pathologist of the German ACC Registry (Wolfgang Saeger, Hamburg, Germany). All samples with a Weiss score of 4 or above were judged as ACC (Weiss et al. 1989). However, in 12 out of the 128 evaluable samples with primary surgery for ACC (9\%) the diagnosis of ACC was made despite a Weiss score of $3(n=7)$ or $2(n=5)$. In these cases, the scores by Hough et al. (1979) and Van Slooten et al. (1985) clearly indicated malignancy. The analysis of the Ki67 index was performed by estimation of the fraction of Ki67 positive nuclei by analyzing at least 30 high-power fields.

Clinical data of ACC patients, including follow-up and survival data, were collected in a structured manner by the German ACC Registry starting (www. nebennierenkarzinom.de). The database for follow-up information was locked in August 2008. Tumor staging at the time of diagnosis was based on imaging studies, corroborated by the findings during surgery and reported according to the UICC/WHO classification 2004 (DeLellis et al. 2004). The secreting status was investigated by appropriate hormonal tests (Fassnacht et al. 2004). Surgical resection of the primary tumor 
was considered complete (R0 resection) if surgical, pathological, and imaging reports did not give any evidence for remaining disease. Presence of distant metastases was evaluated at the time of diagnosis and during follow-up visits by computerized tomography of chest and abdomen. Owing to the retrospective manner of data collection, the imaging interval was not standardized. However, in patients after radical tumor resection imaging was performed usually every three to four months.

Patients gave informed consent for collecting tissue and clinical data and the study was approved by the ethics committee of the University of Wuerzburg (Germany).

\section{Cohort of patients treated with platinum compound}

A subgroup of 45 patients with ACC (18 males, 27 females, mean age at diagnosis: $46.4 \pm 14.4$ years, see also Supplementary Fig. 1), that received at least one cycle (median: 4; range: 1-24) of platinum compounds were investigated separately for the relationship between ERCC1 protein expression, the response to platinum-based chemotherapy and OS. A total of 36 of these patients had been treated with cisplatin, 8 with carboplatin, and 1 with oxaliplatin. The most frequently used protocols were etoposide + doxorubicin + cisplatin $(n=31)$ and carboplatin + etoposide $(n=5)$, cisplatin + etoposide $(n=3)$, but some patients received other combinations including cyclophosphamide $(n=1)$, ifosfamide $(n=1)$, suramin $(n=1)$, doxorubicin $(n=2)$, mitomycin $(n=1)$, or taxotere $(n=1)$. Forty-three patients received concomitant mitotane treatment. None of the patients underwent cytotoxic chemotherapy prior surgical resection. The response to platinum-based treatment was judged according RECIST criteria (Therasse et al. 2000). In this group of patients, imaging for evaluation of therapy was performed every 2-3 months. In the seven patients still alive the median follow-up from the first day of platinum-based drug administration to the last visit was 19 months (range: 9-52).

\section{Tissue samples}

A total of 182 adrenocortical tumors (167 carcinomas and 15 benign lesions) and five normal adrenal samples were assembled into three tissue microarrays (TMAs). Briefly, hematoxylin and eosin stained sections of formalin-fixed and paraffin-embedded tissue blocks were re-evaluated to identify the representative areas of well-preserved morphology. The corresponding area on the block was marked for tissue punching. The TMA was assembled using a commercially available manual tissue puncher/arrayer (Beecher Instruments, Silver Spring, MD, USA) according to the manufacturer's instructions. Five cores with a diameter of $0.6 \mathrm{~mm}$ were punched from each tissue block and arrayed into a recipient paraffin block at a distance of $1 \mathrm{~mm}$ between each core. We chose to array five punch biopsies per case to minimize the number of cases not analyzable due to tissue loss and to increase concordance rates among different cores. A total of 935 adrenocortical tissue cores were placed in three recipient blocks (70, 54 , and 63 cases per block). Sections $(2 \mu \mathrm{m})$ were cut on silanized slides also used for conventional immunohistochemical stains. Before staining, slides were dried at room temperature for 7 days in order to minimize tissue loss. For each block, hematoxylin and eosin stained slides were cut to verify tumor cell content. Samples were only included in the analysis if two or more evaluable cores were available after sectioning and the immunohistochemical staining procedure. In addition, 11 adrenal tissue samples (8 ACCs and 3 normal adrenals glands) placed on standard slides were used to confirm homogeneous staining of ERCC1 and to increase the number of samples from patients treated with platinum-based therapy.

\section{Immunostaining}

Immunohistochemical detection was performed in all samples using an indirect immunoperoxidase technique after high temperature antigen retrieval in $0.01 \mathrm{~mol} / \mathrm{l}$ citrate buffer $(\mathrm{pH} 6.0) 25 \mathrm{~min}$. The primary antibody was a monoclonal mouse antibody against human full-length ERCC1 protein (clone 8F1, Neomarkers, Lab Vision Corp, Fremont, CA, USA; Olaussen et al. 2006, 2007, Zheng et al. 2007). It was used at a dilution of 1:100 and was incubated overnight at $4{ }^{\circ} \mathrm{C}$. The secondary antibody coupled with peroxidase was obtained from Biogenex (Neufahrn, Germany). The slides were incubated with the secondary antibody for $20 \mathrm{~min}$ and washed in PBS before diaminobenzidine as chromogen was applied. After washing in PBS and water, the slides were counterstained in hematoxylin. The negative controls were made using an IgG isotype antibody and by the omission of the primary antibody during the process of immunohistochemical staining. For positive control, endothelial cells in tonsil tissue were chosen (Olaussen et al. 2006, Lee et al. 2008a,b). In addition, cells of the tumor stroma served as internal positive control, if sufficient tumor stroma cells were visible (Olaussen et al. 2006). 


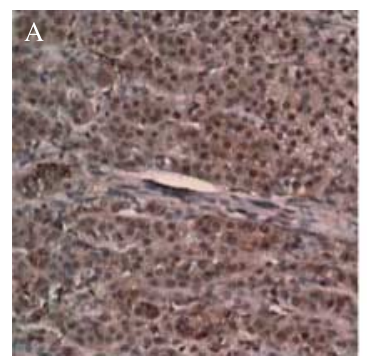

Score 3

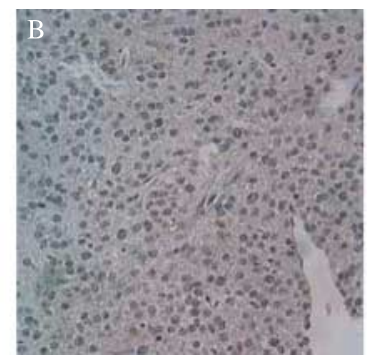

Score 1

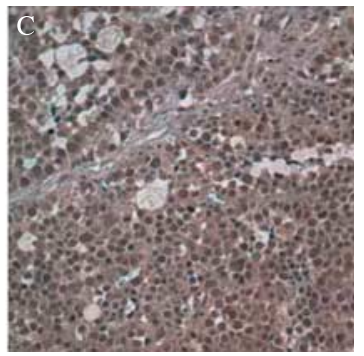

Score 3

Figure 1 Expression of ERCC1 protein in the adrenal tissue. Representative immunohistochemical staining of a normal adrenal gland $(A)$ and two adrenocortical carcinomas (B and $C$ ) with a specific antibody against ERCC1. Intensity was quantified on a scale from 0 (no expression) to 3 (very strong expression); for details see Materials and methods; original magnification $\times 400$.

\section{Microscopical analysis}

Immunostaining results were analyzed using a light microscope at a magnification of $400 \times$. Only samples with positive ERCC1 staining in the nucleus were judged as positive (Fig. 1). ERCC1 staining was homogeneously distributed both in the entire standard tissue slides and among the five cores from the same tissue in the TMAs. We were aiming at the analysis of $>500$ cancer cells. Twelve cases among those assembled in the TMAS with less than two evaluable cores were excluded from statistical analysis. In total, this resulted in 163 evaluable ACCs, 15 adrenocortical adenomas and 8 normal adrenal glands (for details see Table 1). The staining for ERCC1 protein was judged independently by two investigators ( $\mathrm{C} \mathrm{L} \mathrm{R}$ and $\mathrm{L} \mathrm{K}$ ) without knowledge of clinical data. In case of discrepancies, a joined score was agreed on by evaluating the slides together. Staining intensity was evaluated with a grading score of $0,1,2$, or 3 , which corresponded to negative, weak, moderate, or strong staining intensity (Fig. 1). Tonsil tissue was used as reference for an intensity grade of 2 (Olaussen et al. 2006). The percentage of positive tumor cells was calculated for each specimen and scored 0 if $0 \%$ were positive, 0.1 if $1-9 \%, 0.5$ if $10-49 \%$, and 1 if $\geq 50 \%$. A semi-quantitative $H$-score was then calculated by multiplying the staining intensity grading score with the proportion score as previously described (Olaussen et al. 2006). In accordance with this publication an $H$-score $>1$ was a priori chosen as the cut-off point for separating samples with high (ERCC1-high) or low ERCC1 (ERCC1-low) expression.

\section{Statistical analysis}

The primary study hypothesis that ERCC1 expression is a prognostic factor in ACC patients treated with platinum-based chemotherapy was pre-specified and the analysis was performed in a prospective manner. The comparison of clinical and histopathological characteristics was performed using an unpaired

Table 1 Excision repair cross complementing group 1 (ERCC1) protein expression in 186 evaluable samples from adrenal tissues

\begin{tabular}{|c|c|c|c|c|c|c|}
\hline \multirow[b]{2}{*}{$\begin{array}{l}\text { ERCC1 expression } \\
H \text {-score }\end{array}$} & \multirow[b]{2}{*}{$n$} & \multicolumn{2}{|c|}{ Low expression $^{a}$} & \multicolumn{2}{|c|}{ High expression $^{a}$} & \multirow[b]{2}{*}{$\boldsymbol{P}^{*}$} \\
\hline & & 0 & $\begin{array}{c}1 \\
\text { n }(\%)\end{array}$ & 2 & n (\%) & \\
\hline Normal adrenal glands & 8 & 0 & 0 & $4(50 \%)$ & $4(50 \%)$ & \\
\hline Adrenocortical adenomas & 15 & 0 & $1(7 \%)$ & $12(80 \%)$ & $2(13 \%)$ & 1.00 \\
\hline Aldosterone-producing adenoma & 5 & 0 & 0 & 5 & 0 & \\
\hline Cortisol-producing adenoma & 5 & 0 & 0 & 5 & 0 & \\
\hline Inactive adenoma & 5 & 0 & 1 & 2 & 2 & \\
\hline Adrenocortical carcinomas & 163 & $12(7 \%)$ & $76(47 \%)$ & $61(37 \%)$ & $14(9 \%)$ & $0.0007^{\dagger}$ \\
\hline Primary tumor & 132 & 9 & 65 & 46 & 12 & $0.006^{\ddagger}$ \\
\hline Local recurrence & 17 & 2 & 8 & 6 & 1 & \\
\hline Distant metastases & 14 & 1 & 3 & 9 & 1 & \\
\hline
\end{tabular}

${ }^{\star} P$ value evaluated by Fisher's exact test between low and high expression, ${ }^{\dagger} P$ value versus normal adrenal gland, ${ }^{\ddagger} P$ versus benign tumors. $P$ values in bold represent $P<0.05$.

aLow and high ERCC1 expression was defined as $\mathrm{H}$-score $\leq 1$ and $>1$ respectively (for details see Materials and methods, Ref. Gossage \& Madhusudan (2007)). 
Student's $t$-test for continues variables and a Fisher's exact test or a $\chi^{2}$-test for categorical variables, as appropriate. OS was defined as the time from the date of the established ACC diagnosis to death or last follow-up visit. Disease-free survival (DFS) was defined as the time from the date of complete tumor resection to the first radiological evidence of disease relapse or death. In the subgroup of patients treated with platinum-based therapy, survival after platinum (SAP) was calculated from the first day of platinum administration to death or last follow-up visit. KaplanMeier survival analysis was carried out for calculating median duration (and 95\% confidence interval, CI) of DFS, SAP, and OS respectively. Patients alive or disease free were censored at the time of the last visit. The comparisons of OS, DFS, and SAP between

Table 2 Relationship between excision repair cross complementing group 1 (ERCC1) protein expression and baseline clinical or pathological characteristics of 128 patients with adrenocortical carcinoma (only tumor samples derived from primary surgery).

\begin{tabular}{|c|c|c|c|}
\hline \multirow[b]{2}{*}{ Variable } & \multicolumn{2}{|c|}{ ERCC1 expression } & \multirow[b]{2}{*}{$\boldsymbol{P}$} \\
\hline & Low $(H$-score $\leq 1)$ & High $(H$-score $>1)$ & \\
\hline$N$ & 71 & 57 & \\
\hline Age at diagnosis - years & & & 0.59 \\
\hline Median (range) & $48(17-77)$ & $52(18-77)$ & \\
\hline Sex $-n(\%)$ & & & $0.71^{*}$ \\
\hline Male & $25(39)$ & $18(32)$ & \\
\hline Tumor stage (UICC/WHO 2004) - $n(\%)$ & & & $0.50^{\dagger}$ \\
\hline Evaluated patients $(n)$ & 70 & 56 & \\
\hline $\mathrm{I}$ & $2(3)$ & $4(7)$ & \\
\hline II & $27(39)$ & $24(43)$ & \\
\hline III & $17(24)$ & $9(16)$ & \\
\hline IV & $24(34)$ & $19(34)$ & \\
\hline \multicolumn{4}{|l|}{ Hormonal status - $n(\%)$} \\
\hline Evaluated patients $(n)$ & 65 & 50 & \\
\hline Secreting tumors & $49(75)$ & $37(74)$ & $1.00^{*}$ \\
\hline Non-secreting tumors & $16(25)$ & $13(26)$ & \\
\hline Tumor size $(\mathrm{cm})$ & & & 0.72 \\
\hline Median (range) & $11.0(4.5-20.0)$ & $11.5(4.5-23.0)$ & \\
\hline Surgical resection & & & $0.28^{\dagger}$ \\
\hline Evaluated patients & 66 & 54 & \\
\hline Ro & $32(48)$ & $19(35)$ & \\
\hline $\mathrm{R} 1 / \mathrm{RX}$ & $15(23)$ & $18(33)$ & \\
\hline $\mathrm{R} 2$ & $19(29)$ & $17(32)$ & \\
\hline \multicolumn{4}{|l|}{ Medical treatment during follow-up } \\
\hline Mitotane $(n)$ & $50(70)$ & $29(51)$ & 0.42 \\
\hline Cytotoxic chemotherapy & $20(28)$ & $22(39)$ & 0.26 \\
\hline Weiss score & & & 0.78 \\
\hline Evaluated patients $(n)$ & 67 & 54 & \\
\hline Median (range) & $5(2-9)$ & $5(2-8)$ & \\
\hline MIB1 (Ki67) index (\%) & & & 0.04 \\
\hline Evaluated patients $(n)$ & 57 & 53 & \\
\hline Median (range) & $5(0-60)$ & $10(0-50)$ & \\
\hline \multicolumn{4}{|l|}{ Distant metastases at diagnosis } \\
\hline Evaluated patients $(n)$ & 63 & 50 & $0.40^{*}$ \\
\hline Affected patients ( $n(\%))$ & $15(24)$ & $16(32)$ & 0.48 \\
\hline Number of tumoral organs & & & 0.20 \\
\hline Median (range) & $1.0(1-2)$ & $1.5(1-2)$ & \\
\hline Number of tumoral lesions & & & \\
\hline Median (range) & $7.0(1-15)$ & $7.5(2-18)$ & \\
\hline \multicolumn{4}{|l|}{ Follow up (months) } \\
\hline \multirow[t]{2}{*}{ Evaluated patients (still alive) } & 25 & 33 & \\
\hline & $37(6-200)$ & $37(6-150)$ & 0.53 \\
\hline
\end{tabular}

$n$, number; secreting tumors tumor-induced excess of glucocorticoids, androgens, mineralcorticoids, estrogens and/or steroid precursor; R0, complete resection, R1/RX, microscopically incomplete or uncertain resection; R2, macroscopically incomplete resection. $P$ evaluated by Student's $t$-test; ${ }^{*} P$ evaluated by Fisher's exact test; ${ }^{\dagger} P$ evaluated by $\chi^{2}$-test. $P$ values in bold represent $P<0.05$. 
groups were made with log-rank test. Multivariate regression analysis was performed by the Cox proportional hazards regression model to identify those factors that might have significantly influenced survival in platinum-treated patients. For this analysis, all the variables with $P<0.1$ in the univariate analysis were included as continuous or dichotomized variables, as appropriate. The statistical analysis was performed with SPSS (version 15 for Windows, SPSS Inc., Chicago, IL, USA) software. All tests were two-sided and a $P<0.05$ was considered as statistically significant for each analysis.

\section{Results}

\section{Expression of ERCC1 protein in adrenocortical tissue}

As shown in Fig. 1 and as expected, ERCC1 staining was localized to the nucleus. As in all ERCC1 positive specimens the percentage of positive tumor cells was $>50 \%$ (proportion score $=1$ ), the $H$-score (for definition see Materials and methods) corresponded to the respective staining intensity grading score (Table 1). A high ERCC1 nuclear staining intensity $(H$-score $>1)$ was observed in all normal adrenal glands, in 14/15 benign adenomas (93\%), and in 75 of ACCs $(46 \%, P=0.0007$ versus normal adrenals and
$P=0.006$ versus benign tumors, Table 1$)$. Twelve of 163 ACC samples but none of the adenomas and normal adrenal glands were completely negative for ERCC1 staining. There were no significant differences in the proportion of low or high ERCC1 stained samples among ACC primary tumors, local recurrences or distant metastases.

\section{Correlation of ERCC1 with histopathological and clinical characteristics and prognosis}

To evaluate the relation of ERCC1 to histopathological and clinical parameters in ACC, patients were only included in the analysis, when tumor tissue from the primary surgery and complete histological and clinical parameters were available $(n=128,47$ males, 81 females, mean age at diagnosis: $50.0 \pm 16.1$ years). Parameters are summarized in Table 2. No statistically significant differences in age, sex, tumor stage, tumor size, presence of distant metastasis (including number of tumoral organs or metastatic lesions), hormonal status, and Weiss score were found between patients with low and high ERCC1 expression (Table 2). Only the mean MIB1 (Ki67) index was higher in ERCC1high compared with ERCC1-low samples $(13.4 \pm 14.6$ vs $8.2 \pm 11.9 \%, P=0.04$, Table 2 ). In $17 / 53$ samples with high ERCC1 and in $8 / 57$ samples with low ERCC1 Ki67 index was $>10 \%(P=0.039)$.
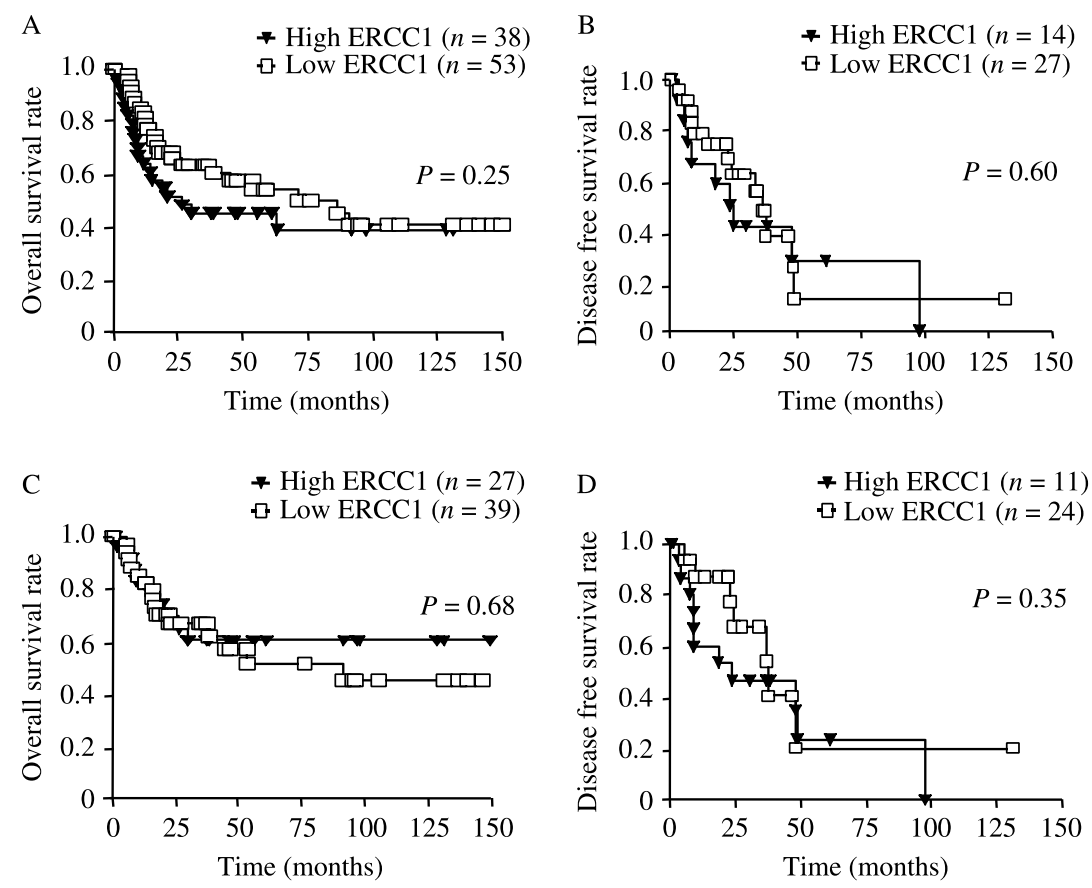

Figure 2 Impact of ERCC1 expression (high $=H$-score $>1$; low $=H$-score $\leq 1$ ) on overall survival (OS) and disease-free survival (DFS) in patients with adrenocortical carcinoma never treated with platinum compounds. (A and B) All patients $(n=91)$; (C and D) patients with tumor stages I and II $(n=66)$. The analysis of DFS was performed only in patients after radical resection. 
Considering altogether the 128 evaluable primary operated ACC patients with full clinical annotation, the OS did not differ significantly between those with low or high ERCC1 expression (Supplementary Fig. 2, which can be viewed online at http://erc.endocrinology-journals.org/supplemental/). For further analysis, patients treated with platinum-based therapy were analyzed separately. In the group of patients who had never received platinum-based regimes $(n=91)$, the median follow-up period from diagnosis to last visit was 47 months (range: 1-200) in the 47 patients still alive. Accordingly, no significant impact of ERCC1 expression was found for both DFS and OS in patients after complete resection and OS in these 91 patients (Fig. 2A and B). Similar results were obtained considering only patients with limited tumor stages (WHO 1 and 2, $n=66$ ) at the time of diagnosis (Fig. 2C and D).

\section{ERCC1 expression and response to platinum-compounds}

In the 45 patients treated with platinum-based chemotherapy, 21 samples $(47 \%)$ showed high ERCC1 expression. No statistically significant differences were observed in clinical and histological characteristics at the time of the diagnosis between patients with low or high ERCC1 staining (Table 3). Types and doses of different platinum-based drugs were comparable between patients with high or low ERCC1 expression (Table 3). Ten patients showed an objective tumor response to treatment $(22.2 \%)$, while seven patients $(15.6 \%)$ had a stable and 28 a progressive disease. In particular, three ERCC1-high patients had a partial response $(14.3 \%)$, while seven ERCC1-low patients $(29.2 \%, P=0.23)$ experienced an objective response (partial response in six and complete response in one). ERCC1-high patients had considerably shorter 1-year and 2-years survival rate after platinum therapy (14 vs $65 \%$ and 5 vs $37 \%$ respectively, both $P<0.001$ ). Accordingly, high ERCC1 expression was significantly associated with poor SAP therapy with a hazard ratio (HR) of 2.95 (95\% CI 1.41-6.17; median SAP: 8 months in patients with high versus 24 months in patients with low ERCC1 expression, Fig. 3A and Table 4). Age over 44 years and Ki67 index $>10 \%$ were also associated with a shorter SAP (HR: 2.08 (95\% CI $1.04-4.18)$ and $2.10 \quad(95 \%$ CI $1.02-4.34))$

Table 3 Clinical and pharmacological data from the 45 patients with adrenocortical carcinoma treated with platinum-compounds

\begin{tabular}{|c|c|c|c|}
\hline Variables at diagnosis & $\begin{array}{l}\text { Low ERCC1 expression } \\
(H \text {-score } \leq 1)\end{array}$ & $\begin{array}{l}\text { High ERCC1 expression } \\
(H \text {-score }>1)\end{array}$ & $P$ \\
\hline$N$ & 24 & 21 & \\
\hline Age - years (median (range)) & $47(22-70)$ & $44(21-73)$ & 0.43 \\
\hline Sex $-n$ males $(\%)$ & $11(46)$ & $6(29)$ & 0.36 \\
\hline Tumor stage - WHO 2004 (median (range)) & $4(1-4)$ & $4(1-4)$ & 0.94 \\
\hline Hormonal status $-n$ secreting tumors (\%) & $20(83)$ & $17(81)$ & 1.00 \\
\hline Tumor size - cm (median (range)) & $12.0(3-19)$ & $11.2(4-25)$ & 0.78 \\
\hline Weiss score (median (range)) & $5.0(3-8)$ & $6.0(4-8)$ & 0.14 \\
\hline MIB1 (ki67) index (median (range)) & $9.0(0-50)$ & $20.0(0-50)$ & 0.10 \\
\hline Distant metastasis - $n(\%)$ & $8(33)$ & $8(38)$ & 0.76 \\
\hline \multicolumn{4}{|l|}{ Information on treatment regimen } \\
\hline Type of platinum compound $(n)$ & & & 0.31 \\
\hline Cisplatin ${ }^{a}$ & $21(87.5)$ & $15(71)$ & \\
\hline Carboplatin ${ }^{\mathrm{b}}$ & $3(12.5)$ & $5(24)$ & \\
\hline Oxaliplatin & 0 & $1(5)$ & \\
\hline Scheme of chemotherapy $(n)$ & & & 0.89 \\
\hline Cisplatin + etoposide + doxorubicin (EDP) & $17(71)$ & $14(67)$ & \\
\hline Carboplatin + etoposide & $2(8)$ & $3(14)$ & \\
\hline Cisplatin + etoposide & $2(8)$ & $1(5)$ & \\
\hline Other schemes ${ }^{c}$ & $3(13)$ & $3(14)$ & \\
\hline Duration of treatment $-n$ cycles (median (range)) & $5.5(1-24)$ & $3.0(1-9)$ & 0.02 \\
\hline Follow up - months (median (range)) ${ }^{d}$ & $11(4-22)$ & $29(6-52)$ & 0.19 \\
\hline Concomitant mitotane $-n(\%)$ & $24(100)$ & $19(90)$ & 0.12 \\
\hline
\end{tabular}

$P$ evaluated by Student's $t$-test or Fisher's exact test or $\chi^{2}$-test, as appropriate.

aedian cumulative dose of cisplatin per cycle was $80 \mathrm{mg} / \mathrm{m}^{2}$.

${ }^{\mathrm{b}}$ Median cumulative dose of carboplatin per cycle was $400 \mathrm{mg} / \mathrm{m}^{2}$.

'Other schemes included: cyclophosphamide $(n=1)$; ifosfamide $(n=1)$; suramin $(n=1)$; mitomycin $(n=1)$ or taxotere $(n=1)$.

dOnly in patients still alive $(n=9)$. 

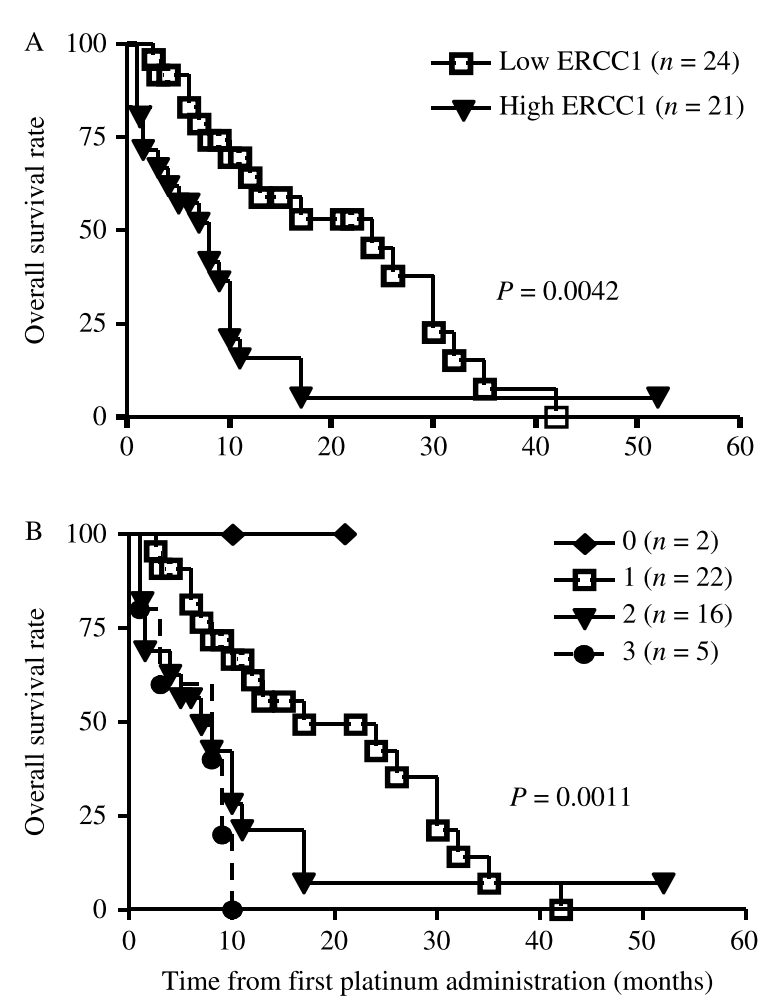

Figure 3 Impact of ERCC1 expression on survival in 45 patients with advanced adrenocortical carcinoma treated with platinum-based chemotherapy. Survival time was calculated from first day of platinum administration to death or last follow-up visit. (A) Patients were divided according to low $(H$-score $\leq 1)$ or high $(H$-score $>1)$ ERCC1 expression. (B) Patients subdivided for graded ERCC1 expression $(H$-score: $0=$ absent; 1 = weak; 2 =moderate; $3=$ strong).

respectively (Table 4). A multivariate logistic regression, including age, Ki67 index and ERCC1 expression (overall model fit, $P=0.013$ by $\chi^{2}$ test), confirmed that high ERCC1 expression was an independent prognostic factor for poor SAP with an adjusted HR of 2.16 (95\% CI 1.04-4.46; $P=0.038$, Table 4). When including in the analysis only patients treated with $\operatorname{EDP}(n=31)$, again patients with high ERCC1 expression had a considerably shorter median survival after EDP (9.5 vs 30.0 months; HR of 2.56 (95\% CI 1.03-6.34), $P=0.043$ ).

Finally, we analyzed survival according to ERCC1 staining intensities $(H$-score $0,1,2,3)$. We observed a correlation between $H$-score and clinical outcome: all patients with an $H$-score of three died early after platinum treatment $(5 / 5$ patients died within 10 months), whereas the two patients with $H$-score 0 (no ERCC1 staining) are still alive at 19 and 35 months respectively, after therapy $(P=0.0011$ by log-rank test for trend, Fig. 3B).

\section{Discussion}

In this study, we have demonstrated for the first time that low ERCC1 protein expression in ACC tumor cells is associated with improved SAP-based chemotherapy. Platinum-based chemotherapies are currently the most frequently used cytotoxic regimens in this very rare malignancy. However, as it is also highlighted in this paper, only a minority of patients responds to this treatment, which is associated with significant toxicity. Thus, our results may have important implications for both individual patients and future treatment concepts. Indeed, ERCC1 is the first molecular parameter associated with prognostic value in advanced ACC and multivariate regression analysis, including all parameters with potential impact in this cohort, confirmed the independent prognostic value of ERCC1 expression on outcome after platinum-based therapy. Moreover, a very strong or an absent ERCC1 expression was even more strikingly correlated with poor or favorable outcome after platinum treatment respectively.

Our results are in accordance with several other studies in different cancer types demonstrating that high ERCC1 expression is associated with poor clinical outcome after administration of platinum-based drugs (Shirota et al. 2001, Fautrel et al. 2005, Joshi et al. 2005, Ceppi et al. 2006, Olaussen et al. 2006, Azuma et al. 2007, Bellmunt et al. 2007, Handra-Luca et al. 2007, Kwon et al. 2007, Lee et al. 2008a,b, Steffensen et al. 2008). As ERCC1 has a crucial role in the nuclear excision repair pathway, its involvement in the resistance to platinum treatment is very plausible (Gazdar 2007, Gossage \& Madhusudan 2007) and most likely responsible for the effects seen in our study, although we cannot fully exclude a confounding role of co-medication like other cytotoxic drugs or mitotane.

We did not find a statistically significant effect of ERCC1 expression on the objective response rate to treatment. However, there was a twofold higher proportion of patients with an objective response to platinum-based therapy in the ERCC1-low group in comparison with the ERCC1-high group suggesting that with a larger sample size this difference may become statistically significant. Of note, some lung cancer studies did also find no significant differences in response rate but in SAP treatment (Azuma et al. 2007, Lee et al. 2008a,b). Therefore, ERCC1 expression may retard the proliferation rate of tumor cells in patients treated with platinum-based therapy independent of objective tumor response. Furthermore, tumor response may not necessarily correlate with survival in all tumor entities (Gollob \& Bonomi 2006). 
Table 4 Predictive factors for overall survival after platinum based therapy in 45 patients with advanced adrenocortical carcinoma (from the first administration of platinum-compounds)

\begin{tabular}{|c|c|c|c|c|c|}
\hline Variable & $n$ & $\begin{array}{l}\text { Median survival } \\
\text { (months) }\end{array}$ & HR & $95 \% \mathrm{Cl}$ & $\boldsymbol{P}^{*}$ \\
\hline \multicolumn{6}{|l|}{ Univariate analysis } \\
\hline Age at diagnosis & & & 2.08 & $1.04-4.18$ & 0.039 \\
\hline$\leq 44$ years & 20 & 8.0 & & & \\
\hline$>44$ years & 25 & 17.0 & & & \\
\hline Sex & & & 1.19 & $0.60-2.35$ & 0.63 \\
\hline Male & 17 & 17.0 & & & \\
\hline Female & 28 & 10.0 & & & \\
\hline Weiss score & & & 0.74 & $0.33-1.54$ & 0.39 \\
\hline Evaluated patients & 40 & & & & \\
\hline$\leq 6$ & 30 & 10.0 & & & \\
\hline$>6$ & 10 & 10.0 & & & \\
\hline Ki67 index & & & 2.10 & $1.02-4.34$ & 0.045 \\
\hline Evaluated patients & 40 & & & & \\
\hline$\leq 10 \%$ & 20 & 14.5 & & & \\
\hline$>10 \%$ & 20 & 8.5 & & & \\
\hline \multicolumn{6}{|l|}{ Distant metastasis } \\
\hline Affected patients & 43 & & & & \\
\hline Tumoral organs ${ }^{a}$ & & & 1.82 & $0.85-3.88$ & 0.12 \\
\hline$\leq 2$ & 27 & 13.0 & & & \\
\hline$n>2$ & 16 & 9.5 & & & \\
\hline Tumoral lesions ${ }^{a}$ & & & 0.94 & $0.44-2.05$ & 0.89 \\
\hline Evaluated patients & 34 & & & & \\
\hline$\leq 6$ & 16 & 11.0 & & & \\
\hline$n>6$ & 18 & 8.0 & & & \\
\hline ERCC1 & & & 2.95 & $1.41-6.17$ & 0.004 \\
\hline Low $(H$-score $\leq 1)$ & 24 & 24.0 & & & \\
\hline High $(H$-score $>1)$ & 21 & 8.0 & & & \\
\hline Variable & & & HR & $95 \% \mathrm{Cl}$ & $P^{\dagger}$ \\
\hline \multicolumn{6}{|l|}{ Multivariate analysis } \\
\hline Age at diagnosis & & & 0.98 & $0.96-1.00$ & 0.14 \\
\hline Ki67 index & & & 1.80 & $0.87-3.72$ & 0.15 \\
\hline ERCC1 expression & & & 2.16 & $1.04-4.46$ & 0.038 \\
\hline
\end{tabular}

The median value for age, Weiss score, Ki67 index, tumoral organs and lesions was used as cut-off values to discriminate the groups. HR, hazard ratio; $\mathrm{Cl}$, confidence interval; $n$, number; ERCC1, excision repair cross complementing group $1 .{ }^{*} P$ evaluated by log-rank test. ${ }^{\dagger} P$ evaluated by Cox proportional hazards regression model (including age as a continuous variable, Ki67 index, and ERCC1 expression as dichotomized variables). $P$ values in bold represent $P<0.05$.

ancluding lesions in the adrenal gland.

Our study has several limitations, mainly the presumably low number of patients, the heterogeneity of platinum-based treatment regimens and the fact that the collection of tumor samples was not performed in a prospective manner. However, the main study hypothesis was pre-specified and the analysis was performed prospectively. In comparison to more common malignancies, the total sample size of 163 ACC patients and 45 evaluated patients after platinum based therapy seems to be small, but for this rare disease it is exceptionally high. No phase III trial for ACC has been published and the largest published phase II trial in ACC enrolled 72 patients (Berruti et al. 2005). Furthermore, the largest series analyzing specific immunohistological parameters in ACC included 124 patients, but detailed analysis was performed only in a subset of 67 and 38 patients respectively (Stojadinovic et al. 2002). Therefore, our study represents the largest series investigating the association of a specific immunohistological marker with clinical outcome. After the publication by Berruti et al. (2005), the EDP regimen is by far the most accepted platinum-based regimen in ACC. Therefore, it is of note, that ERCC1 also predicts outcome in the subgroup of patients treated according to the Berruti protocol $(n=31)$. An additional limitation of our study is related to the use of TMAs for immunohistochemical analysis. In only about fifty percent of tumor samples, a significant 
number of tumor stroma cells were visible to serve as internal positive control for ERCC1 staining.

In several but not all tumor entities, ERCC1 was also of prognostic value in patients not treated with platinum-based therapy (Lee et al. 2008a,b), especially in patients with limited disease (Zheng et al. 2007). However, in our series ERCC1 expression was not related to clinical outcome in patients who never received platinum drugs. This was true for the entire cohort but also for patients with limited disease. Moreover, with the exception of Ki67, we did not find any difference in terms of baseline histopathological or clinical characteristics between ERCC1-low and -high ACC patients. In contrast to ERCC1, Ki67 was not of predictive value for outcome after platinum-based treatment.

The high expression of ERCC1 in benign adrenocortical adenomas and normal adrenals confirms findings in other normal tissues (Gazdar 2007, Gossage $\&$ Madhusudan 2007). Therefore, it has been postulated that a reduced DNA repair capacity may constitute a risk factor for cancer development (Friedberg 2001, Cheng et al. 2002). However, it is currently not clear if low ERCC1 expression is cause or consequence of malignancy.

In conclusion, our findings provide first evidence that ERCC1 protein expression represents a novel independent prognostic factor useful for predicting survival in patients with advanced ACC in whom platinum-based chemotherapy is planned. Thus, it may provide critical information for individualized treatment and optimized patient care in this rare malignancy.

\section{Declaration of interest}

The authors declare that there is no conflict of interest that could be perceived as prejudicing the impartiality of the research.

\section{Funding}

This study was supported by the grants of the Deutsche Krebshilfe (\# 106080 to B A and M F and grant \# 107111 to $\mathrm{M} \mathrm{F}$ ) and the German Ministry of Research BMBF (\#01KG0501 to B A and M F).

\section{Acknowledgements}

This study was part of the German adrenal network GANIMED (German Adrenal Network Improving Treatment and Medical Education). We are grateful to all colleagues who provided tumor material and clinical data for the German ACC registry: The following pathologists provided tumor material from two or more patients for the tissue array: Wolfgang Saeger (Marienkrankenhaus Hamburg); Gerhard Seitz (Klinikum Bamberg); Harald Stein; Manfred Dietel, (Charite University Berlin); Gerhard Mall (Klinikum Darmstadt); Helmut Erich Gabbert (University Hospital Duesseldorf); Werner Schmid (University of Essen); Steffen Hauptmann (Martin-Luther University of Halle); Peter Schirrmacher (University of Heidelberg); Alfred C Feller (University of Luebeck); C James Kirkpatrick (University of Mainz); Roland Moll (University of Marburg); Cyrus Tschahargane (Lukaskrankenhaus, Neuss); Rainer Horst Krech (Klinikum Osnabrueck); Ferdinand Hofstaedter (University of Regensburg); Andrea M Gassel (Leopoldina Hospital Schweinfurt). The following hospitals/clinicians contributed clinical data from three or more investigated patients: Marcus Quinkler; Wolfgang Oelkers (University Hospital Charite Berlin); Michael Morcos (University Hospital Heidelberg); Peter Langer (University Hospital of Marburg); Christian Fottner (University Hospital Mainz); Michael Brauckhoff (University Hospital Halle); Felix Beuschlein (University of Freiburg); Horst L Fehm (University Hospital Luebeck); Dagmar Führer (University Hospital Leipzig); Stefan Petersenn (University Hospital Essen). We are grateful to Wolfgang Saeger (Marienkrankenhaus Hamburg) who confirmed the histopathological diagnoses of all the tumor samples. We appreciate the support of Uwe Maeder (Tumor Center, University Hospital Wuerzburg) in establishing the German ACC registry database and are thankful to Michaela Haaf for documentation.

\section{References}

Abiven G, Coste J, Groussin L, Anract P, Tissier F, Legmann P, Dousset B, Bertagna X \& Bertherat J 2006 Clinical and biological features in the prognosis of adrenocortical cancer: poor outcome of cortisol-secreting tumors in a series of 202 consecutive patients. Journal of Clinical Endocrinology and Metabolism 91 2650-2655.

Ahlman H, Khorram-Manesh A, Jansson S, Wängberg B, Nilsson O, Jacobsson CE \& Lindstedt S 2001 Cytotoxic treatment of adrenocortical carcinoma. World Journal of Surgery 25 927-933.

Allolio B \& Fassnacht M 2006 Clinical review: adrenocortical carcinoma: clinical update. Journal of Clinical Endocrinology and Metabolism 91 2027-2037.

Allolio B, Hahner S, Weismann D \& Fassnacht M 2004 Management of adrenocortical carcinoma. Clinical Endocrinology 60 273-287.

Assiè G, Antoni G, Tissier F, Caillou B, Abiven G, Gicquel C, Leboulleux S, Travagli JP, Dromain C, Bertagna X et al. 2007 Prognostic parameters of metastatic adrenocortical carcinoma. Journal of Clinical Endocrinology and Metabolism 92 148-154.

Azuma K, Komohara Y, Sasada T, Terazaki Y, Ikeda J, Hoshino T, Itoh K, Yamada A \& Aizawa H 2007 Excision repair cross-complementation group 1 predicts 
progression-free and overall survival in non-small cell lung cancer patients treated with platinum-based chemotherapy. Cancer Science 98 1336-1343.

Bellmunt J, Paz-Ares L, Cuello M, Cecere FL, Albiol S, Guillem V, Gallardo E, Carles J, Mendez P, de la Cruz JJ et al. 2007 Gene expression of ERCC1 as a novel prognostic marker in advanced bladder cancer patients receiving cisplatin-based chemotherapy. Annals of Oncology 18 522-528.

Berruti A, Terzolo M, Sperone P, Pia A, Casa SD, Gross DJ, Carnaghi C, Casali P, Porpiglia F, Mantero F et al. 2005 Etoposide, doxorubicin and cisplatin plus mitotane in the treatment of advanced adrenocortical carcinoma: a large prospective phase II trial. Endocrine-Related Cancer 12 657-666.

Ceppi P, Volante M, Novello S, Rapa I, Danenberg KD, Danenberg PV, Cambieri A, Selvaggi G, Saviozzi S, Calogero R et al. 2006 ERCC1 and RRM1 gene expressions but not EGFR are predictive of shorter survival in advanced non-small-cell lung cancer treated with cisplatin and gemcitabine. Annals of Oncology 17 1818-1825.

Chang IY, Kim MH, Kim HB, Lee DY, Kim SH, Kim HY \& You HJ 2005 Small interfering RNA-induced suppression of ERCC1 enhances sensitivity of human cancer cells to cisplatin. Biochemical and Biophysical Research Communications 327 225-233.

Cheng L, Sturgis EM, Eicher SA, Spitz MR \& Wei Q 2002 Expression of nucleotide excision repair genes and the risk for squamous cell carcinoma of the head and neck. Cancer 94 393-397.

Cobo M, Isla D, Massuti B, Montes A, Sanchez JM, Provencio M, Viñolas N, Paz-Ares L, Lopez-Vivanco G et al. 2007 Customizing cisplatin based on quantitative excision repair cross-complementing 1 mRNA expression: a phase III trial in non-small-cell lung cancer. Journal of Clinical Oncology 25 2747-2754.

Cummings M, Higginbottom K, McGurk CJ, Wong OG, Köberle B, Oliver RT \& Masters JR 2006 XPA versus ERCC1 as chemosensitising agents to cisplatin and mitomycin $\mathrm{C}$ in prostate cancer cells: role of ERCC1 in homologous recombination repair. Biochemical Pharmacology 72 166-175.

Darcy KM, Tian C \& Reed E 2007 A Gynecologic Oncology Group study of platinum-DNA adducts and excision repair cross-complementation group 1 expression in optimal, stage III epithelial ovarian cancer treated with platinum-taxane chemotherapy. Cancer Research 67 4474-4481.

DeLellis RA, Lloyd RV, Heitz PU \& Eng C 2004 World Health Organization classification of tumors. Pathology and genetics of tumors of endocrine organs, pp 136. New York, USA: WHO.

Fassnacht M, Kenn W \& Allolio B 2004 Adrenal tumors: how to establish malignancy? Journal of Endocrinological Investigation 27 387-399.
Fassnacht M, Johanssen S, Quinkler M, Bucsky P, Willenberg HS, Beuschlein F, Terzolo M, Mueller HH, Hahner S \& Allolio B 2009 Limited prognostic value of the 2004 UICC staging classification for adrenocortical carcinoma - proposal for a revised TNM classification. Cancer 115 243-250.

Fautrel A, Andrieux L, Musso O, Boudjema K, Guillouzo A \& Langouët S 2005 Overexpression of the two nucleotide excision repair genes ERCC1 and XPC in human hepatocellular carcinoma. Journal of Hepatology 43 288-293.

Friedberg EC 2001 How nucleotide excision repair protects against cancer. Nature Reviews. Cancer 1 22-33.

Gazdar AF 2007 DNA repair and survival in lung cancer the two faces of Janus. New England Journal of Medicine $356771-773$.

Gollob JA \& Bonomi P 2006 Historic evidence and future directions in clinical trial therapy of solid tumors. Oncology 20 (Supp 5) 10-18.

Gossage L \& Madhusudan S 2007 Current status of excision repair cross complementing-group 1 (ERCC1) in cancer. Cancer Treatment Reviews 33 565-577.

Hahner S \& Fassnacht M 2005 Mitotane for adrenocortical carcinoma treatment. Current Opinion in Investigational Drugs 6 386-694.

Handra-Luca A, Hernandez J, Mountzios G, Taranchon E, Lacau-St-Guily J, Soria JC \& Fouret P 2007 Excision repair cross complementation group 1 immunohistochemical expression predicts objective response and cancer-specific survival in patients treated by cisplatinbased induction chemotherapy for locally advanced head and neck squamous cell carcinoma. Clinical Cancer Research 13 3855-3859.

Hough AJ, Hollifield JW, Page DL \& Hartmann WH 1979 Prognostic factors in adrenal cortical tumors. A mathematical analysis of clinical and morphologic data. American Journal of Clinical Pathology 72 390-399.

Joshi MB, Shirota Y, Danenberg KD, Conlon DH, Salonga DS, Herndon JE II, Danenberg PV \& Harpole DH Jr 2005 High gene expression of TS1, GSTP1, and ERCC1 are risk factors for survival in patients treated with trimodality therapy for esophageal cancer. Clinical Cancer Research 11 2215-2221.

Koschker AC, Fassnacht M, Hahner S, Weismann D \& Allolio B 2006 Adrenocortical carcinoma - improving patient care by establishing new structures. Experimental and Clinical Endocrinology and Diabetes 11 445-451.

Kwon HC, Roh MS, Oh SY, Kim SH, Kim MC, Kim JS \& Kim HJ 2007 Prognostic value of expression of ERCC1, thymidylate synthase, and glutathione $S$-transferase P1 for 5-fluorouracil/oxaliplatin chemotherapy in advanced gastric cancer. Annals of Oncology 18 504-509.

Lee HW, Han JH, Kim JH, Lee MH, Jeong SH, Kang SY, Choi JH, Oh YT, Park KJ, Hwang SC et al. $2008 a$ Expression of excision repair cross-complementation group 1 protein predicts poor outcome in patients with small cell lung cancer. Lung Cancer 59 95-104. 
Lee KH, Min HS, Han SW, Oh DY, Lee SH, Kim DW, Im SA, Chung DH, Kim YT, Kim TY et al. $2008 b$ ERCC1 expression by immunohistochemistry and EGFR mutations in resected non-small cell lung cancer. Lung Cancer 60 401-407.

Libè R, Fratticci A \& Bertherat J 2007 Adrenocortical cancer: pathophysiology and clinical management. Endocrine-Related Cancer 14 13-28.

Olaussen KA, Dunant A, Fouret P, Brambilla E, André F, Haddad V, Taranchon E, Filipits M, Pirker R, Popper HH et al. 2006 IALT Bio Investigators DNA repair by ERCC1 in non-small-cell lung cancer and cisplatin-based adjuvant chemotherapy. New England Journal of Medicine 355 983-991.

Olaussen KA, Fouret P \& Kroemer G 2007 ERCC1-specific immunostaining in non-small-cell lung cancer. New England Journal of Medicine 357 1559-1561.

Quinkler M, Hahner S, Wortmann S, Johanssen S, Adam P, Ritte C, Strasburger C, Allolio B \& Fassnacht M 2008 Treatment of advanced adrenocortical carcinoma with erlotinib plus gemcitabine. Journal of Clinical Endocrinology and Metabolism 93 2057-2062.

Reed E 1998 Platinum-DNA adducts, nucleotide excision repair and platinum-based anticancer chemotherapy. Cancer Treatment Reviews 84 331-344.

Schteingart DE, Doherty GM, Gauger PG, Giordano TJ, Hammer GD, Korobkin M \& Worden FP 2005 Management of patients with adrenal cancer: recommendations of an international consensus conference. Endocrine-Related Cancer 12 667-680.

Shirota Y, Stoehlmacher J, Brabender J, Xiong YP, Uetake H, Danenberg KD, Groshen S, Tsao-Wei DD, Danenberg PV \& Lenz HJ 2001 ERCC1 and thymidylate synthase mRNA levels predict survival for colorectal cancer patients receiving combination oxaliplatin and fluorouracil chemotherapy. Journal of Clinical Oncology 19 4298-4304.

van Slooten H, Schaberg A, Smeenk D \& Moolenaar AJ 1985 Morphologic characteristics of benign and malignant adrenocortical tumors. Cancer 55 766-773.
Steffensen KD, Waldstrøm M, Jeppesen U, Brandslund I \& Jakobsen A 2008 Prediction of response to chemotherapy by ERCC1 immunohistochemistry and ERCC1 polymorphism in ovarian cancer. International Journal of Gynecological Cancer 18 702-710.

Stojadinovic A, Ghossein RA, Hoos A, Nissan A, Marshall D, Dudas M, Cordon-Cardo C, Jaques DP \& Brennan MF 2002 Adrenocortical carcinoma: clinical, morphologic, and molecular characterization. Journal of Clinical Oncology 20 941-950.

Terzolo M, Angeli A, Fassnacht M, Daffara F, Tauchmanova L, Conton PA, Rossetto R, Buci L, Sperone P, Grossrubatscher E et al. 2007 Adjuvant mitotane treatment for adrenocortical carcinoma. New England Journal of Medicine 356 2372-2380.

Therasse P, Arbuck SG, Eisenhauer EA, Wanders J, Kaplan RS, Rubinstein L, Verweij J, Van Glabbeke M, van Oosterom AT, Christian MC et al. 2000 New guidelines to evaluate the response to treatment in solid tumors. Journal of the National Cancer Institute 92 205-206.

Tsodikov OV, Ivanov D, Orelli B, Staresincic L, Shoshani I, Oberman R, Schärer OD, Wagner G \& Ellenberger T 2007 Structural basis for the recruitment of ERCC1-XPF to nucleotide excision repair complexes by XPA. EMBO Journal 26 4768-4776.

Wajchenberg BL, Albergaria Pereira MA, Medonca BB, Latronico AC, Campos Carneiro P, Alves VA, Zerbini MC, Liberman B, Carlos Gomes G \& Kirschner MA 2000 Adrenocortical carcinoma: clinical and laboratory observations. Cancer 88 711-736.

Weiss LM, Medeiros LJ \& Vickery AL Jr 1989 Pathologic features of prognostic significance in adrenocortical carcinoma. American Journal of Surgical Pathology 13 202-206.

Zheng Z, Chen T, Li X, Haura E, Sharma A \& Bepler G 2007 DNA synthesis and repair genes RRM1 and ERCC1 in lung cancer. New England Journal of Medicine 356 800-808. 